\title{
Order in disorder: exploring chaos theory in the narrative structure of Chuck Palahniuk's Fight Club
}

\begin{abstract}
Chaologists believe that our actions, albeit small, play prominent roles in shaping the reality which we live in. It is believed that within the chaotic nature of our world, there is a complex system in its randomness. Yet, these seemingly random events have organised patterns such as weather and natural events which may be constantly predicted but they never be completely predetermined. This is the basis of chaos theory which identifies and examines these unseen, disorderly pattern in our world. Similarly, Chuck Palahniuk's Fight Club (1996) tells the story of an unnamed narrator who is trapped in the seemingly disordered string of events. However, there is a point of equilibrium in the unnamed narrator's life before it branches out into the disequilibrium caused by individuals who influence his string of decision when one reads into the text. By utilising main elements of chaos theory and Tzvetan Todorov's narrative theory, this study explores the relationship between the strange attractors and the unnamed narrator's string of decisions. Although the text is narrated in his jumbled train of thoughts, Fight Club's narrative structure can be reconstructed to provide a clearer look on his gradual descent into chaos. As a result, this study shows that there is a parallelism between narratology and quantum physic theory and the possibility to incorporate them in analysing the narrative structure of literature.
\end{abstract}

Keyword: Chaos theory; Butterfly effect; Strange attractors; Todorov's narrative structure; Literature 